\title{
Gamified working memory training in overweight individuals reduces food intake but not body weight
}

Citation for published version (APA):

Dassen, F. C. M., Houben, K., Van Breukelen, G. J. P., \& Jansen, A. (2018). Gamified working memory training in overweight individuals reduces food intake but not body weight. Appetite, 124, 89-98. https://doi.org/10.1016/j.appet.2017.05.009

Document status and date:

Published: 01/05/2018

DOI:

10.1016/j.appet.2017.05.009

Document Version:

Publisher's PDF, also known as Version of record

Document license:

Taverne

Please check the document version of this publication:

- A submitted manuscript is the version of the article upon submission and before peer-review. There can be important differences between the submitted version and the official published version of record.

People interested in the research are advised to contact the author for the final version of the publication, or visit the DOI to the publisher's website.

- The final author version and the galley proof are versions of the publication after peer review.

- The final published version features the final layout of the paper including the volume, issue and page numbers.

Link to publication

\footnotetext{
General rights rights.

- You may freely distribute the URL identifying the publication in the public portal. please follow below link for the End User Agreement:

www.umlib.nl/taverne-license

Take down policy

If you believe that this document breaches copyright please contact us at:

repository@maastrichtuniversity.nl

providing details and we will investigate your claim.
}

Copyright and moral rights for the publications made accessible in the public portal are retained by the authors and/or other copyright owners and it is a condition of accessing publications that users recognise and abide by the legal requirements associated with these

- Users may download and print one copy of any publication from the public portal for the purpose of private study or research.

- You may not further distribute the material or use it for any profit-making activity or commercial gain

If the publication is distributed under the terms of Article $25 \mathrm{fa}$ of the Dutch Copyright Act, indicated by the "Taverne" license above, 


\title{
Gamified working memory training in overweight individuals reduces food intake but not body weight
}

\author{
Fania C.M. Dassen ${ }^{a,}{ }^{*}$, Katrijn Houben ${ }^{\text {a }}$, Gerard J.P. Van Breukelen ${ }^{\mathrm{b}}$, Anita Jansen ${ }^{\mathrm{a}}$

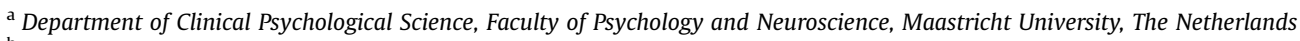 \\ ${ }^{\mathrm{b}}$ Department of Methodology and Statistics, Faculty of Psychology and Neuroscience \& CAPHRI Care and Public Health Research Institute, Maastricht \\ University, The Netherlands
}

\section{A R T I C L E I N F O}

\section{Article history:}

Received 6 February 2017

Received in revised form 6 April 2017

Accepted 3 May 2017

Available online 4 May 2017

\section{Keywords:}

Obesity

Executive functions

Cognitive control

Working memory

Weight loss

Serious gaming

\begin{abstract}
A B S T R A C T
Working Memory (WM) plays a crucial role in successful self-regulation of behavior, including weight regulation. Improving WM might therefore be a promising strategy to support weight loss. In the present study, overweight individuals with a desire to lose weight $(N=91)$ received an online lifestyle intervention, in conjunction with either 25 sessions of gamified WM training (experimental condition) or a sham training (control). Primary outcomes were Body Mass Index (BMI) and food intake at posttest. Secondary outcomes were executive functioning, self-control, eating style, eating psychopathology and healthy eating. Data were analyzed with mixed regression analyses with condition as between-subjects factor (experimental versus control) and time as within-subjects factor (baseline, posttest, FU1 after one month and FU2 after six months). Results revealed that the experimental condition increased their WM span more than control from pretest to posttest, and these gains were retained at FU1, though lost at FU2. No transfer effects of WM training to other executive functioning measures were found. During the bogus taste test at posttest, participants in the experimental condition consumed significantly less than participants in the control condition. However, both conditions showed a small reduction in BMI, improved eating style, reduced eating disorder pathology, and reported more self-control and a healthier eating pattern. In conclusion, the current results provide some evidence that WM training can improve eating behavior at the short term. However, the WM gains were short-lived, and the added value of WM training as an intervention to promote weight loss could not be established. Future studies should test the added value of WM training booster sessions to promote weight loss over a prolonged period of time.
\end{abstract}

(C) 2017 Elsevier Ltd. All rights reserved.

\section{Introduction}

Worldwide, the prevalence of overweight and obesity has increased rapidly in the past 30 years, and has currently reached epidemic proportions (Flegal, Carroll, Kit, \& Ogden, 2012). As a result of environmental changes in lifestyle and food supply during the last centuries, a so-called 'obesogenic environment' has emerged. Because of these environmental changes, significantly less energy is needed to deal with everyday situations, while high caloric foods are available in abundance (Chaput, Klingenberg, Astrup, \& Sjödin, 2011). If the 'energy balance', the relationship between the consumed energy and the energy used for daily

\footnotetext{
* Corresponding author. Department of Clinical Psychological Science, Faculty of Psychology and Neuroscience, Maastricht University, P.O. BOX 616, 6200 MD Maastricht, The Netherlands.

E-mail address: f.dassen@maastrichtuniversity.nl (F.C.M. Dassen).
}

activity, is positive, eventually weight will be gained (Spiegelman \& Flier, 2001). While there are numerous factors that contribute to obesity, the fundamental cause of weight gain concerns a rise in the consumption of energy-dense foods without a corresponding increase in energy expenditure (Hill \& Peters, 1998). In order to promote weight loss, behavioral interventions such as calorierestricting diets and lifestyle interventions are frequently implemented. However, the amount of weight loss achieved via such interventions is, at best, only modest and quickly diminishes again over time (Dansinger, Tatsioni, Wong, Chung, \& Balk, 2007; Douketis, Macie, Thabane, \& Williamson, 2005). Thus, lifestyle interventions seem effective only in the short term, stressing the importance to develop new, effective weight loss interventions.

Being able to resist tempting food requires persistency to longterm health goals and not giving in to immediate pleasures. Based on dual-process theories of behavior, the ability to do this depends on the balance between two cognitive systems that control 
behavior: the reflective or executive system, which promotes reflective, controlled behavior, and the impulsive system, which is responsible for impulsive, automatic behavior (e.g. Hofmann, Friese, \& Strack, 2009; Strack \& Deutsch, 2004). The executive system is necessary to carry out flexible, goal-directed behavior (Hofmann, Schmeichel, \& Baddeley, 2012). From a dual-process perspective, strengthening the executive system (e.g. cognitive control) could increase the capacity to act more towards the achievement of goals and standards (e.g. adherence to a diet), and provide more cognitive control over automatic impulses and behaviors that originate in the impulsive system (e.g. cravings and temptations) (Hofmann et al., 2009).

Working memory (WM) plays a central role in cognitive control (Hofmann et al., 2012). WM is one of the main executive functions (Miyake et al., 2000), and refers to the ability to temporarily store, analyze and manipulate information (Baddeley, 1992). WM is important for focused attention (Barrett, Tugade, \& Engle, 2004), regulation of emotions (Schmeichel, Volokhov, \& Demaree, 2008), suppression of ruminative thoughts (Brewin \& Smart, 2005), down-regulation of cravings (Kavanagh, Andrade, \& May 2005) and to keep mental representations of long-term goals active (Hofmann et al., 2012). Importantly, reduced WM capacity is associated with overweight and obesity (e.g. Gunstad et al., 2007; Smith, Hay, Campbell, \& Trollor, 2011), and with increased food intake, especially in combination with a strong automatic positive attitudes towards foods (e.g. Hofmann, Gschwendner, Friese, Wiers, \& Schmitt, 2008), while higher WM capacity is associated with increased weight loss following lifestyle intervention (Hege et al., 2013). Thus, WM seems crucial for the successful self-regulation of eating behavior and body weight.

Over the past years, several studies have shown that WM capacity can be increased through computerized training (e.g. Diamond \& Ling, 2016; Klingberg, 2010; Morrison \& Chein, 2011). For instance, WM training has been found to decrease ADHD symptoms in children with ADHD (Klingberg et al., 2005), and to reduce alcohol abuse in a sample of heavy drinkers,(Houben, Wiers, \& Jansen, 2011). In a recent study, WM training was also found to reduce pathological ruminative thoughts about food, weight, and body shape, as well as self-reported emotional eating for up to one-month after completion of the training (Houben, Dassen, \& Jansen, 2016). In addition, WM training reduced food intake among highly restrained eaters, though no effects were found on weight loss. However, this study did not take into account whether participants were actually motivated to put in effort to achieve weight loss, and strengthening WM capacity is probably of little use in the absence of such motivation and dieting goals (Hofmann et al., 2012; Houben et al., 2016). Also, WM training in itself is presumably not enough to support weight loss, as improved WM capacity will only be helpful if someone also has sufficient knowledge about what constitutes a healthy lifestyle and which unhealthy behaviors need to be controlled. It would, therefore, probably be more effective to provide WM training together with a lifestyle intervention, thereby directly enhancing the ability to stick to the provided dietary guidelines (Juarascio, Manasse, Espel, Kerrigan, \& Forman, 2015).

In the current study, we examined this possibility. Specifically, in the current study, overweight and obese participants received online psychoeducation about a healthy lifestyle and weight loss, in combination with either WM training or sham training. Hence, participants were provided with the necessary information to change their daily intake in order to achieve weight loss. Because online WM training can be very time consuming and monotonous for participants (Lumsden, Edwards, Lawrence, Coyle, \& Munafò, 2016), we designed the WM training as a serious game. A serious game is a computer-delivered intervention which is both enjoyable and educational (DeSmet et al., 2014). The goal of gamification is to make the boring and repetitive tasks more engaging and fun, thereby heightening motivation of participants and potentially reducing drop-out (Lumsden et al., 2016). We added a surrounding game-shell around the original WM training (Houben et al., 2011, 2016), thereby leaving the training-paradigm structurally intact. The scientific value of the tasks is hereby retained, though the experience and long-term engagement of participants is heightened by adding game elements. Earlier research shows that cognitive tasks can successfully be gamified, without losing its usefulness as a research tool (Lumsden et al., 2016). We also included rewards which became available after a completed session, which were supposed to further increase the external motivation to perform the training (Boendermaker, Prins, \& Wiers, 2015).

The primary outcomes in this study were BMI and food intake. Secondary outcomes were WM performance, self-control, eating style, eating psychopathology and healthy eating. In addition, we also assessed transfer effects of WM training to other measures of executive functions because transfer of WM training to tasks other than the trained tasks is still debated (Diamond \& Ling, 2016; Morrison \& Chein, 2011; Shipstead, Hicks, \& Engle, 2012). We examined the effect of WM training on the outcome measures immediately following training and at 1 -month and 6-month follow-up. It was hypothesized that participants who received WM training would (1) show enhanced performance on a nontrained WM task, (2) show improved executive functions and self-control in daily life, (3) report less pathological thoughts regarding eating, weight and shape, (4) report less emotional and external eating, (5) consume fewer snacks in a laboratory setting at posttest, (6) report healthier eating patterns in daily life, and (7) lose more weight relative to the control condition.

\section{Methods}

\subsection{Participants and design}

Participants were recruited via advertisements in local newspapers, supermarkets, and gyms, via social media, and via a general database managed by our research group. Eligibility criteria for participation were checked via a ten-minutes screening by phone by a research assistant and required that participants were aged 18-60, were overweight (as indexed by a self-reported BMI above 25 ), and motivated to put in effort to achieve weight loss. Motivation was assessed via four statements which were answered on a 5 point Likert scale ranging from (1) 'totally not' to (5) 'extremely'. The items were: (1) 'How important is it for you to lose weight?', (2) 'Do you intend to lose weight from now on?', (3) 'How determined are you to lose weight?' and (4) 'How hard will you try to lose weight?'. In order to meet inclusion criteria, participants had to score at least 3 on all statements. The mean score of eligible participants was $4.04(S D=0.69)$. In addition, basic computer skills were checked, to make sure participants would be able to perform the online training at home. Participants were excluded if they were in treatment for an eating disorder or in the trajectory of bariatric surgery. 


\section{Materials and measures}

\subsection{Conditions: training and control}

The current WM training was developed as a serious game, a game specifically designed to improve cognitive ability (McCallum, 2012), by adding game-elements to the original training. This training was developed by the faculty's engineering department in conjunction with the authors, and was based on the WM trainingparadigm previously used by Houben et al. (2011; 2016). Participants had to perform 25 online WM sessions (experimental condition) or sham sessions (control condition) on a tablet or computer at home. All sessions and tasks were presented in an online restaurant-setting. When participants completed a session, a new item or style to decorate the restaurant became available. This gave participants the opportunity to adjust their restaurant-setting to their personal preferences. See Fig. 1 for images of the gaming interface and training tasks.

To complete a full session, participants had to practice three WM tasks: a visuospatial WM task, a backward digit span task and an object memory task (see Fig. 1). Participants could freely choose the order of the three tasks, consisting of 30 trials each. During the visuospatial WM task, participants monitored a sequence of flashing tables presented within a $4 \times 4$ grid, resembling a dining room. Participants had to reproduce the sequence by clicking or tapping the tables in the right order. During the backward digit span task, a sequence of numbers was shown on a memo board. Participants were instructed to reproduce the presented sequence of numbers in reversed order. During the object memory task, a kitchen cabinet with 16 closed doors was presented. One-by-one the kitchen doors opened, revealing a kitchen-related object. Next, one of the presented objects was shown, and participants had to indicate which of the closed doors was hiding this object.

In the experimental condition, the difficulty level of the tasks was automatically adjusted on a trial-by-trial basis (adaptive WM training; Houben et al., 2016; Houben et al., 2011; Klingberg,
Forssberg, \& Westerberg, 2002). Each task started with a sequence of three items. If the participant responded correctly on two consecutive trials, an item was added to the sequence on the next trial, thereby increasing task difficulty. When participants failed to reproduce the sequence correctly on two consecutive trials, the sequence on the next trial was reduced by one item, thereby decreasing task difficulty. Each new session continued at the same level with which the previous session ended. In the control condition, the difficulty level of the tasks was held constant on a basic, easy level of three items or objects for the entire training (Houben et al., 2011, 2016). In this way we made sure all participants practiced the tasks for an equal amount of trials, though only the experimental condition was expected to train WM by practicing at their optimal capacity limit.

At pretest, posttest, and at follow-up, performance on the practiced training tasks (WM span) was assessed. The assessment tasks started with sequences of three items. When participants responded correctly on two consecutive trials, one item or object was added to the sequence. The task ended when participants failed to reproduce a sequence correctly on two consecutive trials. The outcome measure for each of the three WM assessment tasks was the amount of items or objects in the sequence that could correctly be reproduced. In order to calculate one total score for WM span, the three scores on the WM tasks were averaged.

\subsection{Lifestyle intervention}

All participants received online psychoeducation about weight loss and a healthy lifestyle, while completing the 25 sessions of WM training or sham training at home. The lifestyle intervention included four themed sessions. The first session was available at the start of the training and focused on general principles of weight loss and motivation to lose weight. Participants were advised to keep track of their daily caloric intake via an online tool. The second session addressed topics such as the 'obesogenic' environment, healthy weight loss and nutrition, and participants were
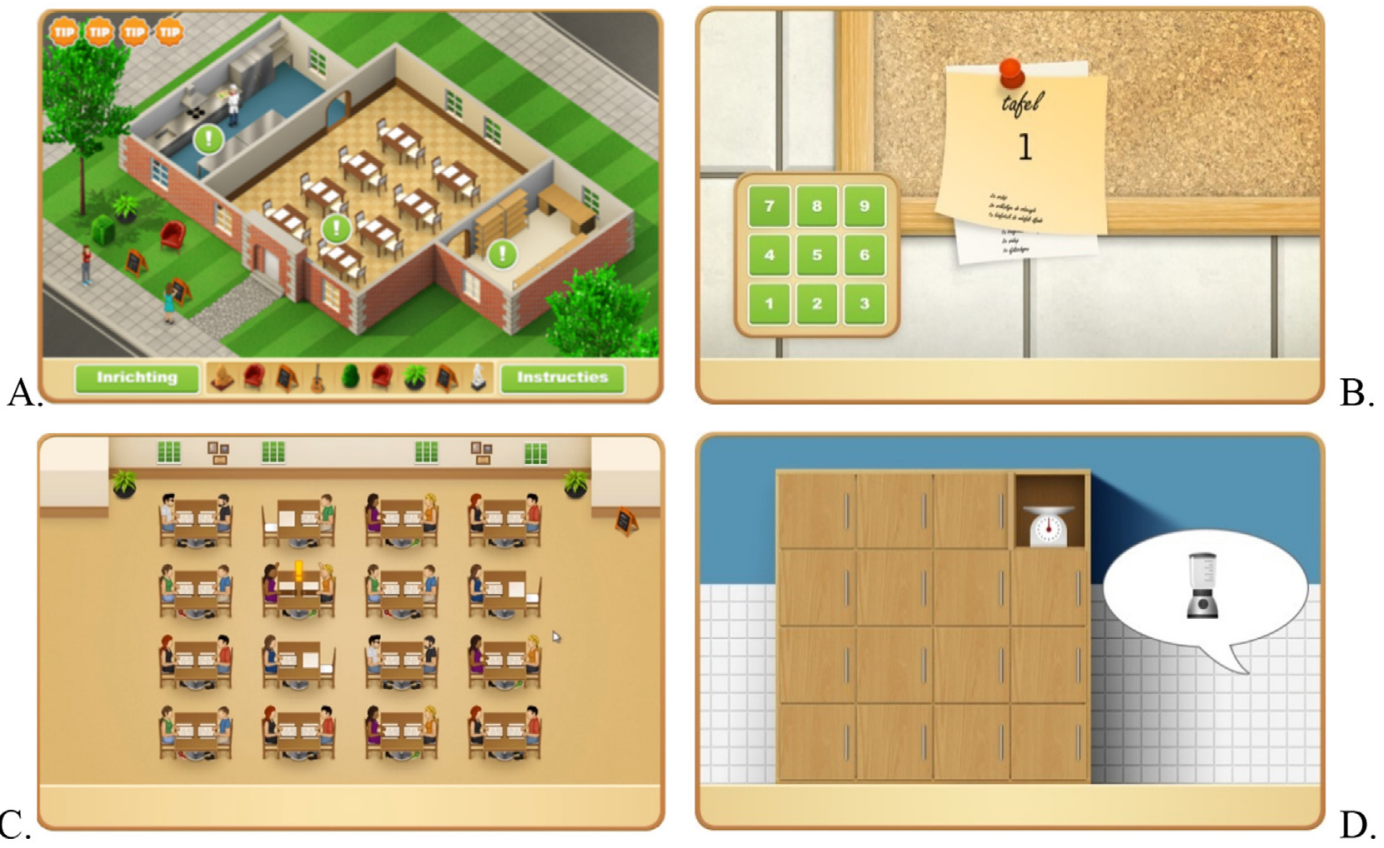

Fig. 1. Images of the WM training: the gaming interface (A), the backward digit span task (B), the visuospatial task (C) and the object memory task (D). 
encouraged to come up with their own personal diet plan. The third lifestyle session addressed several aspects of physical activity, such as the health benefits of regular physical activity and implementing physical activities in daily life. The fourth session discussed strategies for dealing with difficult moments and gave tips to maintain a healthy weight after the intervention. The lifestyle intervention was composed by the first author, using general nutrition information and principles of cognitive behavioral therapy (Beck, 2008). See supplementary material S1 for a more detailed description of the content of every session.

\subsection{2-back task}

The 2-back task is a WM task that predominantly measures the ability to monitor and update WM representations (Jaeggi, Buschkuehl, Perrig, \& Meier, 2010). The 2-back task was used to assess near transfer of WM improvement to a more complex, nontrained WM task. In the current 2-back task (based on Boselie, Vancleef, \& Peters, 2016), participants had to monitor a series of stimuli (i.e., letters), which were presented one-by-one on a computer screen. Participants were instructed to indicate for each letter whether the letter corresponded to the letter that was presented two stimuli before, by pressing either the letter ' $U$ ' (e.g. Yes) or ' $E$ ' (e.g. No) on the keyboard. Participants started with a practice phase, which consisted of 30 trials (10 targets and 20 non-targets). In the end, the accuracy percentage was calculated. If this was above 65 percent, participants continued immediately to the testing phase. However, if the accuracy percentage of the practice phase was below 50 percent, participants had to repeat the practice phase to make sure that they understood the task. An accuracy percentage between 50 and 65 percent gave participants the option to either repeat the practice phase or to continue to the testing phase. In the testing phase, participants completed a total of 90 trials, including 30 targets and 60 non-targets. The outcome variable of interest was accuracy, which was the summation of hits and correct rejections.

\subsection{Restraint scale (RS)}

The RS (Herman \& Polivy, 1980) was assessed at baseline in order to measure the extent to which participants were trying to restrain or control their food intake. Higher scores are indicative of an increased intention to restrict food intake (Cronbach's $\alpha=0.73$ ).

\subsection{Bogus taste test}

At posttest, participants' food intake was measured with a bogus taste test. During the taste test, participants were presented with four bowls containing energy-dense palatable foods and a foodrating form. During the taste test, participants were left alone in the room while the experimenter waited in an adjacent room. The bowls were filled with two different types of salted potato chips (Lays, $541 \mathrm{kcal} / 100 \mathrm{~g}$; AH Excellent, $515 \mathrm{kcal} / 100 \mathrm{~g}$ ) and two different types of milk chocolate buttons (Callebout Select, 563 kcal/100 g; Aldi, $560 \mathrm{kcal} / 100 \mathrm{~g}$ ). Participants were instructed to consume as much or as little as they preferred in order to complete the food ratings. On the food rating form, participants first indicated for how many hours they had not eaten anything, and to what extent they experienced hunger, desire and craving at that moment on a $100 \mathrm{~mm}$ Visual Analogue Scale (VAS) ranging from (0) 'not hungry/no desire/no craving' to (100) 'very hungry/strong desire/ strong craving'. Next, participants had to indicate for each food item how much they liked the food on a VAS ranging from (0) 'not at all' to (100) 'very much liked'. Finally, participants compared and rated the different types of food on various taste dimensions (e.g. 'which product tastes sweeter?'). After $10 \mathrm{~min}$, the experimenter returned and removed the bowls of food. Each bowl was weighted before and after the taste test and grams consumed were converted to calories to calculate the total amount of calories consumed.

\subsection{Behavioral rating of executive functions - adult version (BRIEF-}

A)

The BRIEF-A (Roth \& Gioia, 2005) is a 75 item self-report questionnaire to assess executive functions in daily environment. The BRIEF-A consists of nine subscales: inhibit, shift, emotional control, self-monitor, initiate, working memory, plan/organize, organization of materials, and task monitor. The nine subscales can be combined in one Global Executive Composite (GEC) score. Participants had to indicate for each item whether the statement applied to them on a 3-point Likert scale, with the options 'never', 'sometimes' or 'always'. An example item of the working memory subscale is 'I have trouble with assignments or tasks that require more than one step'. T-values (standardized scores with $M=50$ and $S D=10$, based on a general normative sample: $T \geq 65=$ clinically significant) were calculated with higher T-values reflecting a greater degree of executive dysfunction. In the current study, Tvalues for the GEC (Cronbach's $\alpha=0.96$ ) and the WM subscale were the variables of interest (Cronbach's $\alpha=0.85$ ).

\subsection{Brief Self-Control Scale (brief SCS)}

The brief 13-item SCS was utilized to assess general self-control (Tangney, Baumeister, \& Boone, 2004). On each item, participants had to indicate to what extent they agreed with the statement on a 5-point Likert scale ranging from 'not at all like me' (1) to 'very much like me'(5). Example items are 'I am good at resisting temptation' and 'sometimes I can't stop myself from doing something, even if I know it is wrong'. Higher scores on the SCS indicate higher levels of self-control (Cronbach's $\alpha$ 0.81).

\subsection{Dutch eating behavior questionnaire (DEBQ)}

The DEBQ (Van Strien, Frijters, Bergers, \& Defares, 1986) is a 33item self-report measure with three subscales: emotional eating, external eating and restrained eating. Items are scored on a 5-point Likert scale, ranging from 'never' (1) to 'very often' (5). Means were calculated for only the emotional and external eating subscale, with higher scores indicating increased emotional eating (Cronbach's $\alpha=0.95$ ) or external eating (Cronbach's $\alpha=0.84$ ).

\subsection{Eating disorder examination - questionnaire 6.0 (EDE-Q)}

The EDE-Q 6.0 (Fairburn \& Beglin, 2008) is a 28-item self-report measure of eating disorder pathology, in particular eating, weight and shape concerns. The EDE-Q contains 22 items assessing the frequency and severity of eating disorder psychopathology over the previous 28 days, which are answered on a 7-point Likert scale, ranging from 'not one day' (0) to 'every day' (6) or 'not at all (0) to 'markedly' (6). An example item is: 'On how many of the last 28 days did you had a clear wish to have a completely flat stomach?' Higher total EDE-Q scores are indicative of stronger eating disorder psychopathology (Cronbach's $\alpha=0.89$ ). 


\subsection{Healthy eating behavior}

In order to determine healthy eating behavior in daily life, participants completed a 5-item self-report questionnaire about their eating behavior during the past two weeks (Baker, Little, \& Brownell, 2003; Dassen, Houben, \& Jansen, 2015; Kuijer \& Boyce, $2012,2014)$. The items focused on how often someone (1) ate appropriate portions of food (not too much or too little), (2) ate in a balanced way, with a lot of fruits and vegetables, (3) ate junk food (potato chips, desserts, sweets, candy bars, etc.), (4) overate (kept eating while already satiated), and (5) ate breakfast. Items were answered on a 5-point Likert scale, ranging from 'every day' (1) to 'less than once a week' (5). A total score for healthy eating was calculated (Cronbach's $\alpha=0.65$ ), with higher scores indicating healthier eating behavior during the past two weeks.

\subsection{Body Mass Index (BMI) and percentage BMI-loss}

A digital scale was used to assess the weight of the participants and a measuring stick was used to assess their height. BMI was calculated $\left(\mathrm{kg} / \mathrm{m}^{2}\right)$ as well as percentage BMI-loss relative to baseline [(BMI pre - BMI post)/BMI pre] x 100).

\subsection{Procedure}

All participants were tested individually. Upon arrival, participants were seated behind a computer and the researcher created an online account after which the tasks and questionnaires were completed (see Supplementary material S2 for an overview of all tasks and questionnaires provided in order of administration). Next, participants were asked to remove shoes and any heavy clothing (e.g. jacket) to measure height and weight. The next day, participants started the 25 sessions of online training at home, one session a day. Participants received daily reminders via email. The training was flexible by allowing variable time intervals between sessions: participants were required to perform a minimum of 20 training sessions and a maximum of 25 training sessions, with a minimum interval of $24 \mathrm{~h}$ and a maximum interval of $48 \mathrm{~h}$ between sessions. If participants missed more than five sessions, they dropped out of the study.

After finishing the first, fifth, 10th and 15th WM session, a new lifestyle-session became available in the online training program. The lifestyle-sessions remained accessible during the training. The posttest was scheduled after completion of the training. There was an average of 41.58 days between baseline and posttest $(S D=9.48)$. The first follow-up measurement (FU1) was scheduled one month $(M=31.26$ days, $S D=8.32)$ after completion of the training and the second follow-up (FU2) was scheduled six months $(M=167.48$ days, $S D=10.96$ ) after completion of the training. Participants received gift vouchers of $€ 20$ following completion of the posttest, FU1 and FU2, respectively, resulting in a total remuneration of $€ 60$ for full participation. This study was approved by the Ethical Review Committee of the Faculty of Psychology and Neuroscience (ERCPN) of Maastricht University.

\subsection{Statistical analyses}

The primary analysis was intention-to-treat and included all participants who were randomized. Data were analyzed with mixed regression analysis using maximum likelihood estimation and an unstructured covariance matrix for the repeated outcome measures. Our model was a marginal model with repeated measures nested within persons. Condition was a between-subjects factor ( $1=$ training versus $0=$ control) and time a withinsubjects factor (baseline, posttest, FU1 and FU2, with baseline as reference category and a dummy indicator per other time point). Age, sex (with male as reference category) and education level (with low education level as reference category and dummy indicators for medium and high education level) were included as covariate in all models. Likelihood ratio testing of the covariate by time interaction (with $d f=3$ for age ${ }^{*}$ time and sex*time and $d f=6$ for education*time) was performed to check for significant interactions. The covariate by time interactions were removed from the model if not significant. The effect of training was examined by testing the interaction between time and condition, since no group difference was expected at pretest due to randomization. The final mixed model for each outcome was rerun with restricted maximum likelihood estimation to obtain unbiased standard errors (Verbeke \& Molenberghs, 2000). For the bogus taste test at posttest, caloric intake in the experimental condition was compared with intake in the control condition using ANCOVA, with age, sex, education level and liking of the food included as covariate.

As a manipulation check, the performance on the assessmentversion of the trained tasks (mean WM span) was compared between training and control. Primary outcome measures were BMI (all time points) and snacking behavior (during a bogus taste test at posttest). Secondary outcome measures were accuracy at the 2back task, self-reported executive functioning, self-control (Brief SCS), eating style (external and emotional eating: DEBQ), eating psychopathology (EDE-Q), and healthy eating during the past two weeks. All analyses were two-sided, with an $\alpha$ of 0.05 for primary outcomes and an adjusted $\alpha$ of 0.01 for secondary outcomes to correct for multiple testing.

\section{Results}

\subsection{Baseline}

A total of 91 participants (74.7\% female) met the eligibility criteria, completed the baseline measurement and were randomly assigned to one of two conditions: training $(n=51)$ or control $(n=40)$. Of this sample of participants, $8.8 \%$ received primary education, $38.5 \%$ received secondary education and $52.7 \%$ received higher education. Mean BMI of participants was 30.76 (SD = 3.77), and the mean RS score was $15.61(S D=4.51)$. The mean age of the sample was 47.97 years $(S D=10.69)$ (See $S 3$ in the supplementary material for an overview of all baseline characteristics per condition. None of the differences was significant, all $\mathrm{p}>0.08$, but such baseline tests are not recommended for RCT's, see Moher et al., 2010).

\subsection{Dropout and descriptives at posttest and follow-up}

A total of 21 participants dropped out (5 men, 16 women) from pre-to posttest, due to personal circumstances or because they missed too many training sessions. ${ }^{2}$ In total, 70 participants (18 men, 52 women) completed at least 20 training sessions and the posttest. One participant dropped out from posttest to FU1 and two additional participants dropped out from FU1 to FU2, resulting in a total of 67 participants (experimental condition: $n=34$; control condition: $n=33$ ) who completed all measurements. ${ }^{3}$ In Table 1 observed means (with $S D$ and $n$ ) per condition per time point are displayed for BMI and secondary outcomes. All randomized participants were included in the outcome analyses with all their available data using maximum likelihood estimation, which is a good method to handle missing outcome data (see Verbeke \& Molenberghs, 2000; for details). 
Table 1

Observed means for Body Mass Index $\left(\mathrm{kg} / \mathrm{m}^{2}\right)$ and secondary outcomes, displayed per condition per time point.

\begin{tabular}{|c|c|c|c|c|c|c|c|c|}
\hline & \multicolumn{4}{|l|}{ Experimental condition } & \multicolumn{4}{|l|}{ Control condition } \\
\hline & Baseline (SD) $n=51$ & Posttest (SD) $n=34$ & FU1 (SD) $n=34$ & FU2 (SD) $n=34$ & Baseline (SD) $n=40$ & $\begin{array}{l}\text { Posttest } \\
\text { (SD) } n=36\end{array}$ & $\begin{array}{l}\text { FU1 } \\
(\mathrm{SD}) n=35\end{array}$ & $\begin{array}{l}\text { FU2 } \\
(\mathrm{SD}) n=33\end{array}$ \\
\hline BMI & $30.96(3.64)$ & $29.95(3.46)$ & $29.78(3.56)$ & $29.65(3.80)$ & 30.49 (3.97) & $30.17(4.14)$ & $30.28(4.31)$ & $30.34(4.55)$ \\
\hline 2-back task $k^{1,3}$ & $73.71(12.22)$ & $78.03(9.42)$ & - & - & $75.52(8.18)$ & $75.12(14.07)$ & - & - \\
\hline BRIEF-A: WM subscale & $60.27(10.52)$ & $59.85(12.43)$ & $58.21(12.74)$ & $57.94(13.06)$ & $56.33(10.16)$ & $56.94(10.87)$ & $54.09(11.56)$ & $53.03(9.90)$ \\
\hline BRIEF-A: GEC & $56.47(9.76)$ & $57.38(10.42)$ & $55.03(10.29)$ & $55.47(11.31)$ & $51.90(10.89)$ & $51.94(10.25)$ & $49.83(11.19)$ & $49.64(9.93)$ \\
\hline Brief SCS & $2.97(0.62)$ & $3.08(0.69)$ & $3.28(0.65)$ & $3.17(0.65)$ & $3.23(0.57)$ & $3.29(0.63)$ & $3.36(0.65)$ & $3.39(0.64)$ \\
\hline External eating & $3.09(0.61)$ & $3.00(0.58)$ & $2.87(0.56)$ & $2.88(0.58)$ & $3.04(0.70)$ & $2.80(0.64)$ & $2.72(0.60)$ & $2.65(0.67)$ \\
\hline Emotional eating & $2.77(0.84)$ & $2.58(0.78)$ & $2.45(0.80)$ & $2.52(0.91)$ & $2.69(0.86)$ & $2.53(0.90)$ & $2.38(0.87)$ & $2.43(0.92)$ \\
\hline EDE-Q & $2.56(0.78)$ & $2.24(0.67)$ & $1.94(0.91)$ & 1.93 (0.95) & $2.30(0.86)$ & $1.98(0.62)$ & $1.73(0.94)$ & $1.61(0.89)$ \\
\hline Healthy eating & $18.88(3.44)$ & $20.15(2.80)$ & $20.74(3.01)$ & $20.56(2.31)$ & $18.90(3.43)$ & $20.53(2.47)$ & $20.17(3.10)$ & $20.15(2.96)$ \\
\hline
\end{tabular}

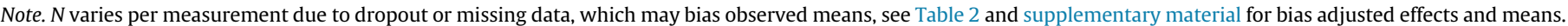

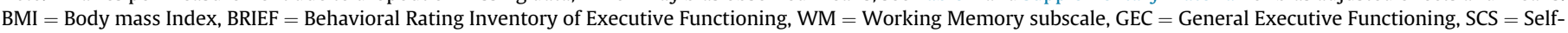
Control Scale, EDE-Q = Eating Disorders Examination - Questionnaire.

\subsection{Manipulation check}

Completion of one online WM session took on average $25.71 \mathrm{~min}(S D=31.56)$ for the control condition and $38.44 \mathrm{~min}$ $(S D=25.51)$ for the experimental condition. ${ }^{4}$ The control condition missed on average 0.92 sessions $(S D=1.52)$ and the experimental condition missed on average 1.85 sessions $(S D=1.73)$. The total number of completed sessions varied between 20 and 25 $(M=23.63, S D=1.68)$. The training was on average completed within 33.57 days $(S D=7.98)$. The control condition practiced every day at the same level of three items, whereas the experimental condition showed a steady increase in number of items that could be recalled during the online training at home (see supplementary material S4 for an overview of the number of items that could be

\footnotetext{
${ }^{1}$ Participants also performed the 2-back task at FU1 and FU2. However, due to a programming error, the practice-trial was not kept constant for all participants, allowing a part of the sample to practice only once at FU1, regardless of accuracylevel at the practice-session. At FU2, all participants were only allowed to practice once. This unintended protocol violation (i.e. less practice permitted) introduced bias, and therefore data at F1 and F2 was not analyzed for the 2-back task. The mixed regression model therefore only included the change from baseline to posttest.

${ }^{2}$ Logistic regression was performed to assess the difference between participants who completed the training and participants who dropped out during the training. The participants who dropped out did not differ from the participants who finished the training in terms of BMI, sex, education level or RS (all $p>0.24$ ). However, both age and condition ( $1=$ training versus $0=$ control) were predictive of dropout. Participants who dropped out were somewhat younger compared to the rest of the sample, $B=-0.06, p=0.04$, and more often in the experimental condition, $B=1.50$, $p=0.02$. All randomized participants were included in the analysis, even if they were only measured at baseline, and age, sex and education level were included as covariates in all analyses, using maximum likelihood estimation. This method of treatment effect estimation is valid without imputation of missing outcome values even if dropout is related to treatment or covariates or the baseline of the outcome at hand (Verbeke \& Molenberghs, 2000).

3 Due to a technical error in the saving of responses, data of the 2-back task was lost at random for some participants, resulting in a sample of $n=74$ at baseline and $n=64$ at posttest.

4 Note that beginning and end time per practiced task at home was recorded automatically, though from these data cannot be derived whether participants spent all the time actively on the training, or took some breaks in between. The difference between conditions with respect to the mean time per session was not statistically significant, $t(1,67)=1.83, p>0.05$. One participant was excluded from this particular analysis, because the mean time per session for this person was a clear outlier ( $M=510.90 \mathrm{~min})$.

${ }^{5}$ Regarding the 2-back data, there was one outlier identified on the bottom end of the data at baseline and three outliers were identified on the bottom end of the data at posttest. These scores were replaced by the nearest value which was not an outlier minus one point for the outlier identified at baseline, and minus one, two and three points for the outliers identified at posttest. The analyses without adjustment for outliers also showed no condition*time interaction $(p>0.085)$.
}

recalled daily during the 25 sessions of the online training).

The performance on the assessment-version of the trained tasks (WM span) after completion of the training was compared between training and control by testing the interaction between time and condition. Age, sex and education level were included as covariates. None of the interactions of covariate by time were significant, and therefore not included in the final model. Likelihood ratio testing of the group by time interaction (i.e. comparing the -2loglikelihood of the model with versus without the interaction, see Verbeke \& Molenberghs, 2000) showed significant interaction, with $\chi 2$ $(d f=3)=16.94, p=<0.01$. More specifically, in the control group the score increased by about 1 from pretest to posttest and hardly changed from there on. In the experimental group the score increased by 2 from pretest to posttest and FU1, and then dropped to the level of the control group at FU2. See Fig. 2 for a graphical display of results.

\subsection{Bogus taste test}

Seventy participants completed the bogus taste test at posttest due to dropout during the training. One participant could not perform the taste test because of medical dietary restrictions, and was therefore excluded from this analysis, resulting in a sample of

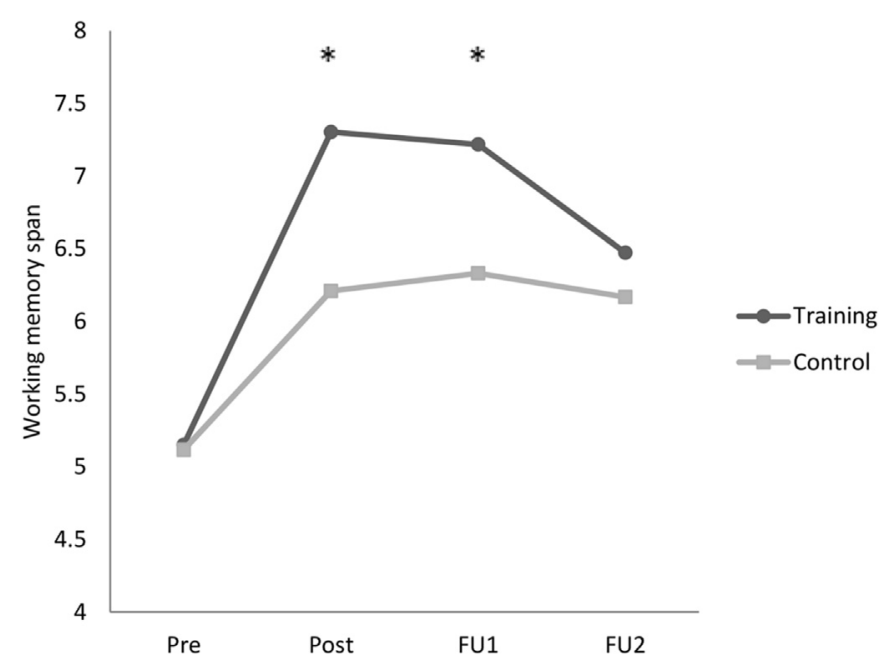

Fig. 2. Estimated means of working memory span (number of items of trained tasks that could be correctly recalled at pretest, posttest, follow-up 1 and follow-up 2) based on the final model (REML). The average of the three trained tasks (working memory span) is displayed. Note. ${ }^{*}$ indicates significant differences at $p<0.05$. 
69 participants (experimental: $n=34$; control: $n=35$ ). Caloric intake ranged from $5.72 \mathrm{kcal}$ to $295.90 \mathrm{kcal}$. Training and control condition did not differ on hunger, desire, craving, or liking of the snacks (all $p>0.69$ ). On average, participants rated their liking of the food with a score of 51.29 on a scale of $0-100(S D=18.03$, range 16.25-100). A one-way ANCOVA was conducted to compare food intake during the bogus taste test between training and control, with age, sex, education level and participants' liking of the food included as a covariate. Results revealed liking as a significant predictor of caloric intake, $F(1,63)=6.20, p=0.02$. None of the other covariates were significant predictors of intake (all $p>0.50$ ). Importantly, a significant difference between the two conditions on food intake was found, $F(1,63)=4.17, p<0.05$, 95\% CI for mean difference $[-65.45,-0.71]$. This indicates that participants in the experimental condition (estimated marginal mean $=72.86$, $S E=11.41)$ consumed significantly less calories than participants in the control condition (estimated marginal mean $=105.94$, $S E=11.25$ ) during the bogus taste test.

We explored post-hoc potential moderators of this effect. Dietary restraint (RS) at baseline and craving were first standardized and entered as continuous predictor in the ANCOVA. The interaction between RS and condition did not reach significance, $F(1,61)=0.26, p=0.61$. The interaction between craving and condition did reach significance, $F(1,61)=7.62, p<0.01$. Next, we analyzed the effect of the training separately for participants with high versus low craving (respectively 1 SD above and 1 SD below the mean score; Cohen et al., 2003). For participants with low craving (-1 SD), there was no significant difference between training and control with respect to food intake (mean difference 9.96, 95\% CI [-32.45-51.47], $F(1,61)=1.22, p=0.64)$. For participants with high craving $(+1 S D)$, food intake was higher in the control condition compared to the experimental condition (mean difference $72.89,95 \%$ CI [30.04-115.74], $F(1,61)=11.57, p=0.001$.)

\subsection{Body Mass Index}

None of the interactions of covariate by time were significant, and these were therefore not included in the final mixed regression model. Within this final model consisting of covariate main effects, condition, time and condition by time interaction, the latter interaction was not significant either (LR test: $\chi 2(d f=3)=3.52$, $p=0.32$; see Table 2 ). This indicates that there were no differences in weight loss between conditions (see S6 and S7 in the supplementary material for more details). The non-significant interaction between time and condition was next removed from the model, to test the main effect of time, showing a very small but significant decrease of BMI from pretest to all other time points (see
Table 3). On the average, participants lost a total of respectively $1.26 \%$ of their BMI at posttest, $1.52 \%$ at FU1 and $1.61 \%$ at FU2 relatively to baseline. The main effect of condition was not significant $(p>0.47)$, as expected given the randomized assignment and absence of condition by time interaction. We explored post-hoc dietary restraint (RS) as potential moderator for BMI. However, within the model consisting of covariate main effects, condition, RS, time, time by condition interaction, RS by condition interaction, time by RS interaction, and the three-way interaction between RS, time and condition, the latter interaction was not significant (LR test: $\left.\chi^{2}(d f=3)=0.79, p=0.85\right)$.

\subsection{Secondary outcomes}

None of the interactions of covariate by time were significant, and these were therefore not included in the final model. Within that model, the condition by time interaction was not significant either (all $p>0.10$ for all secondary outcomes according to the LR test of the model with versus without interaction, remember that alfa $=0.01$ for secondary outcomes in view of multiple testing; see Table 2 for more details). The models were rerun with only condition and time as predictors included, corrected for age, sex and education level, to test for possible main effects of time, relative to baseline. See Table 3 for an overview of the main results. The main condition effect was never significant in these models (all $p>0.07$ ). Participants showed improvement on the 2-back task at posttest. They reported improved WM in daily life one month after finishing the training relative to baseline, and effects were retained at FU2. Participants also indicated improved self-control at FU1 and FU2. Regarding eating style, self-reported emotional eating was decreased at FU1 and FU2, but not directly after the training at the posttest. Participants reported less external eating at posttest, at FU1 and at FU2. Pathological thoughts regarding eating, weight and shape were decreased at posttest, and improvements were retained at FU1and FU2. At the same time, participants indicated to eat healthier at posttest, FU1 and FU2.

\section{Discussion}

It was investigated whether a gamified WM training in combination with an online lifestyle intervention would lead to improved self-regulation and increased weight loss compared to a lifestyle intervention combined with sham training. On average, participants lost a small amount of weight, though the WM training did not result in additional weight loss compared to lifestyle intervention. However, the training did result in less food intake immediately after training. Results further showed a stronger

Table 2

Condition by time effects on Body Mass Index $\left(\mathrm{kg} / \mathrm{m}^{2}\right)$ and secondary outcomes, established with mixed linear regression $(N=91)$

\begin{tabular}{|c|c|c|c|c|}
\hline & Condition (SE) & Condition*posttest (SE) & Condition*FU1 (SE) & Condition*FU2 (SE) \\
\hline BMI & $0.43(0.84)$ & $0.08(0.18)$ & $-0.09(0.24)$ & $-0.24(0.36)$ \\
\hline 2-back task ${ }^{1,5}$ & $-1.55(2.31)$ & $3.10(2.00)$ & - & - \\
\hline BRIEF-A: WM subscale & $4.04(2.25)$ & $-2.33(1.37)$ & $-1.71(1.45)$ & $-1.02(1.68)$ \\
\hline BRIEF-A: GEC & $3.53(2.21)$ & $0.38(1.02)$ & $-0.52(1.22)$ & $-0.04(1.57)$ \\
\hline Brief SCS & $-0.20(0.13)$ & $0.02(0.07)$ & $0.18(0.09)$ & $0.06(0.08)$ \\
\hline External eating & $0.00(0.14)$ & $0.01(0.08)$ & $-0.03(0.09)$ & $-0.01(0.11)$ \\
\hline Emotional eating & $0.06(0.17)$ & $-0.20(0.12)$ & $-0.20(0.13)$ & $-0.18(0.16)$ \\
\hline EDE-Q & $0.24(0.16)$ & $-0.05(0.11)$ & $-0.12(0.16)$ & $-0.02(0.18)$ \\
\hline Healthy eating & $0.09(0.76)$ & $-0.41(0.69)$ & $0.50(0.77)$ & $0.45(0.76)$ \\
\hline
\end{tabular}

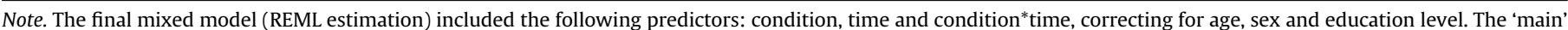

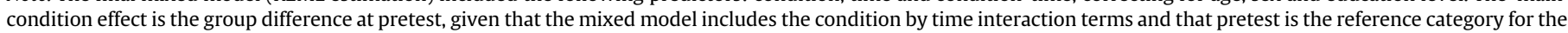
dummy coding of time. The condition*time effect is the group difference with respect to the change from baseline to this time point.

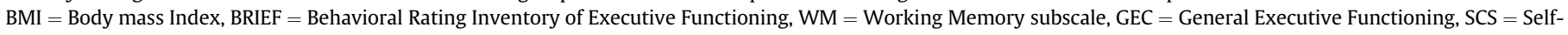
Control Scale, EDE-Q = Eating Disorders Examination - Questionnaire. 
Table 3

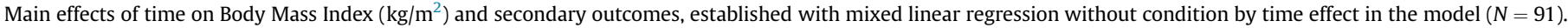

\begin{tabular}{|c|c|c|c|c|}
\hline & Condition (SE) & Posttest (SE) & FU1 (SE) & FU2 (SE) \\
\hline BMI & $0.60(0.83)$ & $-0.37(0.09)^{* *}$ & $-0.43(0.12)^{* *}$ & $-0.48(0.18)^{*}$ \\
\hline 2-back task ${ }^{1,5}$ & $0.14(2.04)$ & $2.68(1.01)^{* *}$ & - & - \\
\hline BRIEF-A: WM subscale & $3.95(2.23)$ & $-0.41(-0.70)$ & $-2.46(0.73)^{* *}$ & $-2.94(-0.84)^{* *}$ \\
\hline BRIEF-A: GEC & $3.89(2.13)$ & $0.48(0.50)$ & $-1.45(0.61)$ & $-1.19(0.78)$ \\
\hline Brief SCS & $-0.17(0.13)$ & $0.05(0.04)$ & $0.17(0.04)^{* *}$ & $0.11(0.04)^{* *}$ \\
\hline External eating & $-0.01(0.13)$ & $-0.15(0.04)^{* *}$ & $-0.25(0.04)^{* *}$ & $-0.26(0.05)^{* *}$ \\
\hline Emotional eating & $-0.02(0.16)$ & $-0.16(0.06)$ & $-0.29(0.06)^{* *}$ & $-0.23(0.08)^{* *}$ \\
\hline EDE-Q & $0.21(0.14)$ & $-0.30(0.06)^{* *}$ & $-0.57(0.08)^{* *}$ & $-0.63(0.09)^{* *}$ \\
\hline Healthy eating & $0.20(0.52)$ & $-1.28(0.34)^{* *}$ & $-1.41(0.39)^{* *}$ & $-1.28(0.38)^{* *}$ \\
\hline
\end{tabular}

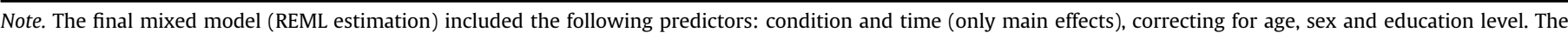

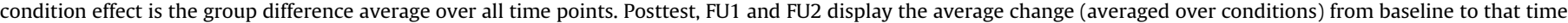
point.

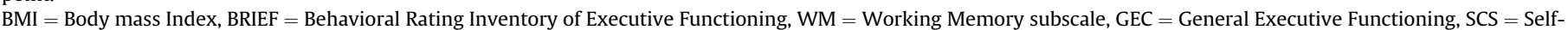
Control Scale, EDE-Q = Eating Disorders Examination - Questionnaire.

${ }^{*} p<0.05,{ }^{* *} p<0.01 ; \alpha=0.05$ for Body Mass Index and $\alpha=0.01$ for secondary outcomes.

increase in WM capacity in the experimental condition compared to control at posttest, and these gains were retained at one month follow-up, in line with Houben et al. (2016). In the literature there were some indications of prolonged improvements of WM following training (e.g. Holmes, Gathercole, \& Dunning, 2009; Jaeggi, Buschkuehl, Jonides, \& Shah, 2011). However, the current results stress the importance of continuous practicing, as gains in WM relative to control were lost at the six month follow-up measurement. As the effect seems to decay over time, booster WM training sessions could potentially elongate training effects. Hence, we encourage future studies to explore the potential added value of booster sessions. The control condition also showed an increase in performance on the WM tasks of the training. This was probably due to practice effects, though we cannot exclude the possibility that a sham training also caused (smaller) improvements of WM capacity.

The 2-back task was included as an examination of near transfer effects to a non-trained WM task. However, no significant difference between conditions after the training could be demonstrated. Unfortunately, due to technical problems, data of the 2-back task was lost for a part of the sample, and practice conditions were not equal for every measurement, resulting in that the data could not be analyzed at follow-up measurements. Previous research showed somewhat mixed results regarding reliability of the 2-back task, as correlations with other WM tasks are for instance often low (Jaeggi et al., 2010). The current study therefore provided only a limited test of near transfer effects. On self-reported executive functioning in daily life, as measured with the BRIEF-A, also no differences between conditions were found. Performance-based measures and ratings of executive function assess different underlying processes (Toplak, West, \& Stanovich, 2013): Cognitive tasks are well structured and performed under optimal circumstances, capturing the processing efficiency of cognitive abilities, whereas self-report measures assesses the extent to which someone is achieving his/ her goals in daily life. The current study did not find evidence for transfer-effects to other WM measures, though due to several limitations, results should be interpreted with caution. Further research should include a more expanded test battery of WM tasks and self-report measures to study possible transfer-effects.

Interestingly, a significant difference in caloric intake during the bogus taste test after completion of the training was found. Participants in the experimental condition consumed less of the snacks relative to control. Clearly, the WM training helped these participants to act more in line with their goal to lose weight (Hofmann et al., 2008, 2012). Post-hoc analyses showed that craving moderated the effect of training on food intake. Specifically, at low levels of craving, there was no difference in caloric intake between training and control. At high levels of craving, in contrast, intake was significantly reduced in the training conditions relative to control. Hence, these findings indicate that the training is most effective in reducing intake when there is a strong impulse to consume food (i.e., craving) that requires self-regulation (cf. Hofmann et al., 2008). However, note the explorative nature of this analysis, which requires further replication. Houben et al. (2016) found that only highly restrained participants reduced their intake after WM training. In the current study, no such moderation by restraint was found but note that we included only participants who were motivated to achieve weight loss. As a limitation, it should be noted that food intake was only measured at posttest, and therefore it is unclear whether effects on food intake were retained at follow-up. We also did not directly measure real-world caloric intake, for instance with a food diary, as food diaries are often prone to bias and recall error. Instead, we included a laboratory-based taste test as a more reliable measure of actual food intake. However, it would be interesting for future studies to also track changes in daily food intake.

Both the experimental and control condition showed improvements over time in self-reported external and emotional eating, self-control in general, eating disorder pathology regarding shape, eating and weight, and healthy eating patterns, for up to six months after the training. In line with these results, both conditions lost a small amount of weight during the intervention period, which was retained at follow-up. The observed reduction in weight from pretest to follow-up could have been due to the lifestyle sessions provided, or simply to the fact that participants took part in an intervention for weight loss. To disentangle these effects, future research could include two extra conditions, receiving only WM training or sham training without a lifestyle intervention. Because the main focus was to examine the effectiveness of WM training, we did not specifically form or test hypotheses on the effectiveness of the lifestyle intervention. It would nevertheless be interesting for future study to explore whether participants made specific changes in their dietary intake in response to the lifestyle intervention and what types of dietary changes they were attempting to make. With respect to the main aim of the study, however, the present findings show no indication that supplementing a lifestyle intervention with WM training has any added value in reducing emotional eating, pathological thoughts related to shape, eating and weight, unhealthy eating patterns, or weight. A month is however a relatively short period of time to lose a significant amount of weight. 
Effects on BMI can perhaps only be expected after a prolonged period of time, as participants need time to be able to apply their increased WM capacity to weight loss strategies. In the current study, the increase in WM capacity was not maintained at six month follow-up, and therefore effects of the training on weight loss could not be anticipated due to training effects. Here as well, it would thus be interesting to examine the value of booster WM training sessions on body weight.

The current study examined the effectiveness of a general WM training. However, it would also be interesting to tailor the trainings sessions to the domain of weight loss and dieting. For instance, in inhibition training, practicing inhibition with food items (behavior-specific training) seems more effective than inhibition training in general (e.g. Allom, Mullan, \& Hagger, 2016; Houben \& Jansen, 2015; Houben, Nederkoorn, \& Jansen, 2014). Perhaps the same idea applies to WM training. Some evidence suggests that food-specific WM capacity is a stronger predictor of dieting success than general WM capacity. For instance, Meule (2016) found that successful dieters did perform better than non-successful dieters on n-back task with food stimuli relative to general stimuli, and Hege et al. (2013) showed that differences in brain activity during a food-specific n-back task were related to successful weight loss following lifestyle treatment. Food-specific WM may be more relevant in predicting weight loss compared to general WM, for instance, because one needs to keep track of the amount of calories already consumed to be able to stick to one's diet, and because food cues have to be monitored to select when and what to eat (Boutelle \& Kirschenbaum, 1998). Further, it is possible that palatable food cues activate executive functioning in successful dieters, leading to more control over eating behavior (Meule, 2016), and it has been suggested that food-specific WM training may also reduce food cue reactivity (Jansen, Houben, \& Roefs, 2015; Meule, 2016). It would therefore be interesting for future studies to explore the effectiveness of food-specific WM training on eating behavior and weight loss. From the current literature, it is also not clear what type of WM is most important in the regulation of eating behavior. A recent study provides evidence for the relationship between better visuospatial WM and healthy food intake and dietary success (see Whitelock, Nouwen, Van den Akker, \& Higgs, 2018). According to these results, the current training did target the right components. Future studies should explore the role of the specific WM sub-components in the regulation of eating behavior further, as the effectivity of WM training could be further enhanced by focusing on the specific subcomponents involved in eating behavior and weight loss.

Strengths of the current study are the inclusion of an active control group and the inclusion of follow-up measurements for up to six months following training. The current study is also representative of the general population (i.e. by using a community sample). Unfortunately, the current study also had a relatively high rate of dropout during the online training (23\%), which was comparable to the study of Houben et al. (2016) (18\%), despite the serious game format of the WM training. A lack of time to complete the sessions was provided as the main reason for dropout, as sessions were considered to be very time consuming. Yet every intervention requires effort, and participants should be prepared to invest time and energy. It is not clear from prior research how many sessions of WM training are needed to be efficient. A shorter training might have led to higher adherence while still preserving the efficacy of the training. Future studies should explore the optimal amount of training sessions regarding adherence and efficiency. Interestingly, more participants of the experimental condition dropped out as compared to those randomized to control. This could be because the training took more effort to complete, as trials were more challenging. Future studies should try to keep the effort equal between conditions. Also, future studies could compare the standard, nongame WM training with our gamified training, to see whether both produce equal outcomes.

In conclusion, current results show that WM can be improved, though we found no evidence for wide transfer effects to daily life and the added value of WM training as a weight loss intervention could not be demonstrated. However, the current study did show reduced food intake immediately following WM training. Hence, it may be premature to conclude that WM training is not effective at all, since at least in the short-term WM training affected food intake. We therefore encourage other researchers to replicate and extend the current findings.

\section{Acknowledgements}

This project was funded by the Maastricht University Interfaculty Program 'Eatwell'.

We want to thank Berber Jacquemijns for assisting in the recruitment, screening and data collection. We are grateful to Michiel Vestjens and Richard Benning for designing and programming the gamified version of the WM training and their excellent assistance during the execution of the study.

\section{Appendix A. Supplementary data}

Supplementary data related to this article can be found at http:// dx.doi.org/10.1016/j.appet.2017.05.009.

\section{References}

Allom, V., Mullan, B., \& Hagger, M. (2016). Does inhibitory control training improve health behaviour? A meta-analysis. Health Psychology Review, 10(2), 168-186. Baddeley, A. (1992). Working memory. Science, 255(5044), 556.

Baker, C. W., Little, T. D., \& Brownell, K. D. (2003). Predicting adolescent eating and activity behaviors: The role of social norms and personal agency. Health Psychology, 22(2), 189-198.

Barrett, L. F., Tugade, M. M., \& Engle, R. W. (2004). Individual differences in working memory capacity and dual-process theories of the mind. Psychological Bulletin, $130(4), 553$.

Beck, J. S. (2008). Beck's dieetoplossing: Uitgeverij Nieuwezijds.

Boendermaker, W. J., Prins, P. J., \& Wiers, R. W. (2015). Cognitive Bias Modification for adolescents with substance use problems-Can serious games help? Journal of Behavior Therapy and Experimental Psychiatry, 49, 13-20.

Boselie, J. J., Vancleef, L. M., \& Peters, M. L. (2016). The effects of experimental pain and induced optimism on working memory task performance. Scandinavian Journal of Pain, 12, 25-32.

Boutelle, K. N., \& Kirschenbaum, D. S. (1998). Further support for consistent selfmonitoring as a vital component of successful weight control. Obesity Research, 6(3), 219-224.

Brewin, C. R., \& Smart, L. (2005). Working memory capacity and suppression of intrusive thoughts. Journal of Behavior Therapy and Experimental Psychiatry, 36(1), 61-68.

Chaput, J. P., Klingenberg, L., Astrup, A., \& Sjödin, A. M. (2011). Modern sedentary activities promote overconsumption of food in our current obesogenic environment. Obesity Reviews, 12(5), e12-e20.

Cohen, J., Cohen, J., Cohen, P., West, S. G. A., Leona, S., Patricia Cohen, S. G. W., et al. (2003). Applied multiple regression/correlation analysis for the behavioral sciences.

Dansinger, M. L., Tatsioni, A., Wong, J. B., Chung, M., \& Balk, E. M. (2007). Metaanalysis: The effect of dietary counseling for weight loss. Annals of Internal Medicine, 147(1), 41-50.

Dassen, F. C., Houben, K., \& Jansen, A. (2015). Time orientation and eating behavior: Unhealthy eaters consider immediate consequences, while healthy eaters focus on future health. Appetite, 91, 13-19.

DeSmet, A., Van Ryckeghem, D., Compernolle, S., Baranowski, T., Thompson, D., Crombez, G.,...Van Cleemput, K. (2014). A meta-analysis of serious digital games for healthy lifestyle promotion. Preventive Medicine, 69, 95-107.

Diamond, A., \& Ling, D. S. (2016). Conclusions about interventions, programs, and approaches for improving executive functions that appear justified and those that, despite much hype, do not. Developmental Cognitive Neuroscience, 18, 34-48.

Douketis, J., Macie, C., Thabane, L., \& Williamson, D. (2005). Systematic review of long-term weight loss studies in obese adults: Clinical significance and applicability to clinical practice. International Journal of Obesity, 29(10), 1153-1167.

Fairburn, C. G., \& Beglin, S. J. (2008). Eating disorder examination questionnaire. In C. Fairburn (Ed.), Cognitive behaviour therapy and eating disorders. Guilford 
Press. Unpublished translation by Anita Jansen, Maastricht.

Flegal, K. M., Carroll, M. D., Kit, B. K., \& Ogden, C. L. (2012). Prevalence of obesity and trends in the distribution of body mass index among US adults, 1999-2010. Jama, 307(5), 491-497.

Gunstad, J., Paul, R. H., Cohen, R. A., Tate, D. F., Spitznagel, M. B., \& Gordon, E. (2007). Elevated body mass index is associated with executive dysfunction in otherwise healthy adults. Comprehensive Psychiatry, 48(1), 57-61.

Hege, M. A., Stingl, K., Ketterer, C., Häring, H.-U., Heni, M., Fritsche, A., et al. (2013). Working memory-related brain activity is associated with outcome of lifestyle intervention. Obesity, 21(12), 2488-2494.

Herman, C. P., \& Polivy, J. P. (1980). Restrained eating. In A. J. Stunkard (Ed.), Obesity (pp. 208-225). Philadelphia: Saunders.

Hill, J. O., \& Peters, J. C. (1998). Environmental contributions to the obesity epidemic. Science, 280(5368), 1371-1374.

Hofmann, W., Friese, M., \& Strack, F. (2009). Impulse and self-control from a dualsystems perspective. Perspectives on Psychological Science, 4(2), 162-176.

Hofmann, W., Gschwendner, T., Friese, M., Wiers, R. W., \& Schmitt, M. (2008). Working memory capacity and self-regulatory behavior: Toward an individual differences perspective on behavior determination by automatic versus controlled processes. Journal of Personality and Social Psychology, 95(4), 962.

Hofmann, W., Schmeichel, B. J., \& Baddeley, A. D. (2012). Executive functions and self-regulation. Trends in Cognitive Sciences, 16(3), 174-180.

Holmes, J., Gathercole, S. E., \& Dunning, D. L. (2009). Adaptive training leads to sustained enhancement of poor working memory in children. Developmental Science, 12(4), F9-F15.

Houben, K., Dassen, F. C. M., \& Jansen, A. (2016). Taking control: Working memory training in overweight individuals increases self-regulation of food intake. Appetite, 105, 567-574.

Houben, K., \& Jansen, A. (2015). Chocolate equals stop. Chocolate-specific inhibition training reduces chocolate intake and go associations with chocolate. Appetite, 87, 318-323.

Houben, K., Nederkoorn, C., \& Jansen, A. (2014). Eating on impulse: The relation between overweight and food-specific inhibitory control. Obesity, 22(5), 968-975.

Houben, K., Wiers, R. W., \& Jansen, A. (2011). Getting a grip on drinking behavior training working memory to reduce alcohol abuse. Psychological Science, 22, 968-975.

Jaeggi, S. M., Buschkuehl, M., Jonides, J., \& Shah, P. (2011). Short-and long-term benefits of cognitive training. Proceedings of the National Academy of Sciences, 108(25), 10081-10086.

Jaeggi, S. M., Buschkuehl, M., Perrig, W. J., \& Meier, B. (2010). The concurrent validity of the N-back task as a working memory measure. Memory, 18(4), 394-412.

Jansen, A., Houben, K., \& Roefs, A. (2015). A cognitive profile of obesity and its translation into new interventions. Frontiers in Psychology, 6.

Juarascio, A. S., Manasse, S. M., Espel, H. M., Kerrigan, S. G., \& Forman, E. M. (2015). Could training executive function improve treatment outcomes for eating disorders? Appetite, 90, 187-193.

Kavanagh, D. J., Andrade, J., \& May, J. (2005). Imaginary relish and exquisite torture: The elaborated intrusion theory of desire. Psychological Review, 112(2), 446.

Klingberg, T. (2010). Training and plasticity of working memory. Trends in Cognitive Sciences, 14(7), 317-324

Klingberg, T., Fernell, E., Olesen, P. J., Johnson, M., Gustafsson, P. Dahlström, K.,...Westerberg, H. (2005). Computerized training of working memory in children with ADHD-a randomized, controlled trial. Journal of the American Academy of Child \& Adolescent Psychiatry, 44(2), 177-186.
Klingberg, T., Forssberg, H., \& Westerberg, H. (2002). Training of working memory in children with ADHD. Journal of Clinical and Experimental Neuropsychology, 24(6), 781-791.

Kuijer, R. G., \& Boyce, J. A. (2012). Emotional eating and its effect on eating behaviour after a natural disaster. Appetite, 58(3), 936-939.

Kuijer, R. G., \& Boyce, J. A. (2014). Chocolate cake. Guilt or celebration? Associations with healthy eating attitudes, perceived behavioural control, intentions and weight-loss. Appetite, 74, 48-54.

Lumsden, J. Edwards, E. A., Lawrence, N. S., Coyle, D., \& Munafò, M. R. (2016). Gamification of cognitive assessment and cognitive training: A systematic review of applications and efficacy. JMIR Serious Games, 4(2).

McCallum, S. (2012). Gamification and serious games for personalized health Studies in Health Technology and Informatics, 177, 85-96.

Meule, A. (2016). Dieting and food cue-related working memory performance. Frontiers in Psychology, 7.

Miyake, A., Friedman, N. P., Emerson, M. J., Witzki, A. H., Howerter A., \& Wager, T. D. (2000). The unity and diversity of executive functions and their contributions to complex "frontal lobe" tasks: A latent variable analysis. Cognitive Psychology 41(1), 49-100.

Moher, D., Hopewell, S., Schulz, K. F., Montori, V., Gøtzsche, P. C. Devereaux, P. J., ... Altman, D. G. (2010). CONSORT 2010 explanation and elaboration: Updated guidelines for reporting parallel group randomised trials. BMJ 340. http://dx.doi.org/10.1136/bmj.c869.

Morrison, A. B., \& Chein, J. M. (2011). Does working memory training work? The promise and challenges of enhancing cognition by training working memory Psychonomic Bulletin \& Review, 18(1), 46-60.

Roth, R. M., \& Gioia, G. A. (2005). Behavior rating inventory of executive function-adult version: Psychological Assessment Resources Lutz, FL.

Schmeichel, B. J., Volokhov, R. N., \& Demaree, H. A. (2008). Working memory capacity and the self-regulation of emotional expression and experience. Journal of Personality and Social Psychology, 95(6), 1526.

Shipstead, Z., Hicks, K. L., \& Engle, R. W. (2012). Cogmed working memory training: Does the evidence support the claims? Journal of Applied Research in Memory and Cognition, 1(3), 185-193.

Smith, E., Hay, P., Campbell, L., \& Trollor, J. (2011). A review of the association between obesity and cognitive function across the lifespan: Implications for nove approaches to prevention and treatment. Obesity Reviews, 12(9), 740-755.

Spiegelman, B. M., \& Flier, J. S. (2001). Obesity and the regulation of energy balance. Cell, 104(4), 531-543.

Strack, F., \& Deutsch, R. (2004). Reflective and impulsive determinants of social behavior. Personality and Social Psychology Review, 8(3), 220-247.

Tangney, J. P., Baumeister, R. F., \& Boone, A. L. (2004). High self-control predicts good adjustment, less pathology, better grades, and interpersonal success. Journal of Personality, 72(2), 271-324.

Toplak, M. E., West, R. F., \& Stanovich, K. E. (2013). Practitioner Review: Do performance-based measures and ratings of executive function assess the same construct? Journal of Child Psychology and Psychiatry, 54(2), 131-143.

Van Strien, T., Frijters, J. E., Bergers, G., \& Defares, P. B. (1986). The Dutch Eating Behavior Questionnaire (DEBQ) for assessment of restrained, emotional, and external eating behavior. International Journal of Eating Disorders, 5(2), 295-315.

Verbeke, G., \& Molenberghs, G. (2000). Linear mixed models for longitudinal data. Springer.

Whitelock, V., Nouwen, A., Van den Akker, O., \& Higgs, S. (2018). The role of working memory sub- components in food intake and dieting behaviours. Appetite. 